\title{
PENGARUH UKURAN SPESIMEN TERHADAP HUBUNGAN TEGANGAN DAN REGANGAN PADA BETON HIGH VOLUME FLY ASH SELF COMPACTING CONCRETE
}

\author{
Effect of Size Specimens on Stress-Strain Behavior of High Volume Fly ash - Self Compacting Concrete \\ (HVFA-SCC)
}

\author{
Fitria Rindang Nur Insyiroh(c), Agus Setiya Budi(b) Senot Sangadji(c) \\ a,b,c Civil Engineering Department, Sebelas Maret University, Indonesia
}

\begin{abstract}
ABSTRAK
Fly ash merupakan limbah dari sisa pembakaran batu bara yang berbentuk partikel amorf yang penggunaannya di sunia konstruksi masih berkisar 10\%-30\%. Penggunaan fhy ash dengan kadar minimal 50\% sebagai pengganti semen disebut dengan High Volume Fly Ash Concrete (HVFAC). High Volume Fly Ash Self Compacting Concrete (HVFA-SCC) merupakan perpaduan antara beton yang menggunakan kadar fly ash tinggi dan dapat memadat sendiri. Benda uji yang digunakan berbentuk silinder dengan variasi diameter $5 \mathrm{~cm}, 7,5 \mathrm{~cm}$, dan $11 \mathrm{~cm}$ dengan masing - masing variasi tinggi $10 \mathrm{~cm}, 15 \mathrm{~cm}$, dan $22 \mathrm{~cm}$. Rancang campur yang digunakan pada High Volume Fly Ash Self Compacting Concrete menggunakan teknologi Self-Compacting Concrete (SCC) berdasar EFNARC Specification and Guidelines for Self-Compacting Concrete, 2002. Hasil dari penelitian ini menunjukkan bahwa perbedaan ukuran spesimen benda uji silinder dengan rasio perbandingan diameter dan tinggi yang tetap akan menghasilkan karakteristik yang relatif hampir sama pada umur 28 hari. Dengan kuat desak HFVA-SCC lebih rendah dibanding beton normal, dengan rata-rata penurunan sebesar $20 \%$. Penggunaan fly ash sebagai pengganti semen meningkatkan $8,5 \%$ nilai indeks tonghness dibandingkan dengan beton normal. Daktilitas beton HVFA-SCC lebih tinggi 30\% dibandingkan beton normal.
\end{abstract}

Kata Kunci : size effect, tegangan regangan; fly ash; beton memadat mandiri, tonghness, daktilitas

\section{ABSTRACT}

Fly ash is a waste of coal combustion in the form of amorphous particles whose use in construction is still around $10 \%-30 \%$. The use of fly ash with a minimum of 50\% as a substitute for cement is called High Volume Fly Ash Concrete (HVFAC). High Volume Fly Ash Self Compacting Concrete (HVFA-SCC) is a combination of concrete that uses high fly ash and can solidify itself. The test specimens used were cylindrical with variation diameter $5 \mathrm{~cm}, 7.5 \mathrm{~cm}, 11 \mathrm{~cm}$ with each variation height $10 \mathrm{~cm}, 15 \mathrm{~cm}, 22 \mathrm{~cm}$. The mixed design used in High Volume Fly Ash Self Compacting Concrete uses Self-Compacting Concrete (SCC) technology based on EFNARC Specification and Guidelines for Self-Compacting Concrete, 2002. The results of this study indicate that the difference in the size of specimens of cylindrical test specimens with the ratio of diameter And a fixed beight will yield relatively similar characteristics at 28 days of age. HVFA-SCC have lower compression strength of concrete compared to normal concrete with an average decrease $20 \%$. The use of fly ash as substitute for cement increasing 8,5\% of toughness value. HVFA-SCC concrete ductility is higher with value $30 \%$ than normal concrete.

Keywords: size effect; stress-strain; fly ash; Self-compacting concrete, toughness, ductility 


\section{Pendahuluan}

Dalam perkembangan konstruksi diperlukan kemampuan beton dengan tingkat fluidity tinggi agar beton dapat mengisi rongga-rongga udara yang seringkali masih ada saat pengecoran beton tanpa menggunakan vibrator. Beton jenis ini sering disebut sebagai Self Compacting Concrete (SCC). Beton jenis ini akan mengisi semua celah di tempat pengecoran dengan memanfaatkan berat sendiri campuran beton. (Ladwing, II - M., Woise, F., Hemrich, W. and Ehrlich,N. 2001).

Penggunaan filler dan bahan pozzolan pada Self Compacting Concrete akan mempengaruhi porositas beton, sehingga didapatkan komponen yang padat. Poz:olan adalah bahan yang mempunyai silika atau silika alumina yang memiliki sedikit atau tidak ada sifat semen tetapi apabila dalam bentuk butiran yang halus dan dengan kehadiran kelembaban, bahan ini dapat bereaksi dengan kapur bebas (kalsium hidroksida) yang dilepaskan semen pada proses hidrasi dan membentuk senyawa yang bersifat mengikat pada temperatur normal dengan adanya air.

Pada High Volume Fly Ash Concrete penggunaan fly ash sebagai pengganti sebagian semen memiliki beberapa keungguluan yaitu lebih ramah lingkungan karena memanfaatkan limbah sekaligus mengurangi jumlah penggunaan semen, meningkatkan workability dan durability, dan diharapkan mampu meningkatkan kekuatan beton (Stefanus dan Howard, 2010). Inovasi beton HVFAC ini jika dikombinasikan dengan jenis beton self compacting concrete membentuk beton dengan kemampuan workability dan durability yang baik. Karena butiran fly ash yang berbentuk bulat akan memudahkannya mengalir mengikuti berat sendiri dari beton segar dan mampu mengisi ruang ruang kosong antar agregat. Pada High Volume Fly Ash - Self Compacting Concrete (HVFA - SCC) kemampuan beton untuk mengalir tanpa menggunakan air akan semakin meningkat, juga kemampuan beton untuk mempertahankan bentuk akan semakin baik karena fly ash memiliki fungsi menambah kepadatan beton.

\section{Metode Penelitian}

\section{Mix Design}

Material untuk beton normal \& HVFA-SCC dapat dilihat pada Tabel 1. dngan besar maksimal agregat kasar yang digunakan $10 \mathrm{~mm}$. Penelitian ini menggunakan dua jenis desain rancang campur yaitu untuk beton normal dan HVFA-SCC. Perancangan proporsi campuran beton normal menggunakan metode SNI 03-2834-2000 (Tata Cara Pembuatan Rencana Campuran Beton Normal). Rancang campur mix design untuk HVFA-SCC mengacu pada EFNARC Specification and Guidelines for Self-Compacting Concrete, 2002.

Tabel 1. Mix Design HVFA-SCC dan Beton Normal

\begin{tabular}{|c|c|c|c|c|c|c|c|}
\hline Kode & $\begin{array}{c}\text { Kadar } \\
\text { Fly Ash }\end{array}$ & $\begin{array}{l}\text { Semen } \\
\left(\mathrm{kg} / \mathrm{m}^{3}\right)\end{array}$ & $\begin{array}{l}\text { Fly Ash } \\
\left(\mathrm{kg} / \mathrm{m}^{3}\right)\end{array}$ & $\begin{array}{l}\text { Kerikil } \\
\left(\mathrm{kg} / \mathrm{m}^{3}\right)\end{array}$ & $\begin{array}{c}\text { Pasir } \\
\left(\mathrm{kg} / \mathrm{m}^{3}\right)\end{array}$ & $\begin{array}{c}\text { Air } \\
\left(1 \mathrm{t} / \mathrm{m}^{3}\right)\end{array}$ & $\begin{array}{c}\mathrm{Sp} \\
\left(1 \mathrm{t} / \mathrm{m}^{3}\right)\end{array}$ \\
\hline HVFA-SCC & $50 \%$ & 384,3 & 384,3 & 709,8 & 595,35 & 231 & 7,686 \\
\hline NORMAL & $0 \%$ & 750 & - & 782,42 & 566,58 & 231 & - \\
\hline
\end{tabular}




\section{Pengujian Benda Uji}

Hasil uji slump pada beton segar untuk beton normal bernilai $13 \mathrm{~cm}$. Sementara hasil pengujian slum flow pada HVFA-SCC disajikan pada Tabel 2.

Tabel 2. Slump flow HVFA-SCC

\begin{tabular}{cccc}
\hline \multirow{2}{*}{ Kode } & \multicolumn{3}{c}{ Parameter } \\
\cline { 2 - 4 } & diameter & $\mathbf{t 5 0 0}(\mathbf{s e c})$ & Velocity $(\mathrm{mm} / \mathbf{s e c})$ \\
\hline HVFA-SCC & 750 & 3,61 & 138,5 \\
\hline
\end{tabular}

Benda yang digunakan berjumlah 3 sampel dengan ukuran diameter $50 \mathrm{~mm}, 75 \mathrm{~mm}$, dan 110 $\mathrm{mm}$ dengan masing-masing tinggi $100 \mathrm{~mm}, 150 \mathrm{~mm}$, dan $220 \mathrm{~mm}$ untuk beton normal dan HVFA-SCC. Benda uji kemudian di curing dalam keadaan lembab dalam waktu 28 hari dan selanjutnya diuji tekan menggunakan Universal Testing Macbine (UTM). Untuk kecepatan pembebanan (load rate) pada penelitian ini didasarkan pada ASTM C-39M dengan menggunakan strain rate control sebesar $0,3 \mathrm{~mm} /$ menit. Hasil yang didapatkan dari UTM berupa besarnya gaya pembebanan $(\mathrm{N})$ dan besarnya deformasi $(\mathrm{mm})$. Dari hasil ini akan diolah menjadi grafik tegangan dan regangan.

\section{Hasil Penelitian}

Tabel 3. Hasil pengujian kuat desak benda uji HVFA-SCC dan Beton Normal

\begin{tabular}{|c|c|c|c|}
\hline \multirow[t]{2}{*}{ No } & \multirow{2}{*}{ Tipe Benda Uji } & \multicolumn{2}{|c|}{ Kuat Tekan (MPa) } \\
\hline & & HVFA-SCC & Beton Normal \\
\hline \multirow[t]{3}{*}{1} & \multirow{3}{*}{ Silinder $5 \mathrm{~cm} \times 10 \mathrm{~cm}$} & 28,53 & 42,07 \\
\hline & & 30,76 & 38,82 \\
\hline & & 26,20 & 40,51 \\
\hline \multirow[t]{3}{*}{2} & \multirow[t]{3}{*}{ Silinder $7,5 \mathrm{~cm} \times 15 \mathrm{~cm}$} & 26,03 & 28,08 \\
\hline & & 25,14 & 30,89 \\
\hline & & 25,95 & 25,95 \\
\hline \multirow[t]{3}{*}{3} & \multirow[t]{3}{*}{ Silinder $11 \mathrm{~cm}$ x $22 \mathrm{~cm}$} & 26.40 & 34,64 \\
\hline & & 23,68 & 37,80 \\
\hline & & 26,44 & 21,79 \\
\hline
\end{tabular}

Berdasarkan hasil pengujian terlihat bahwa perbedaan ukuran spesimen sampel beton dengan perbandingan rasio diameter dan tinggi yang tetap tidak berpengaruh signifikan pada kuat tekan beton HVFA-SCC maupun beton normal. Kuat tekan HVFA-SCC pada sampel yang sama lebih rendah dibanding beton normal. 
Berikut merupakan hasil grafik tegangan HVFA-SCC dengan beton normal:

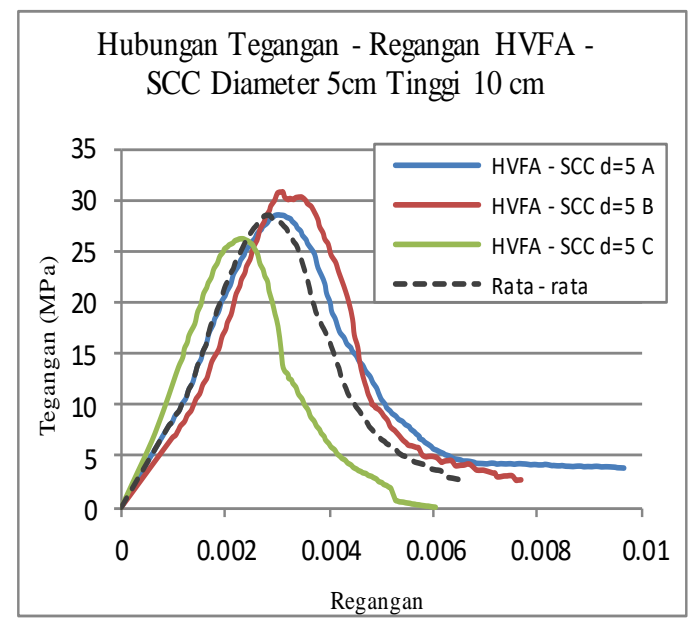

$1 \mathrm{a}$

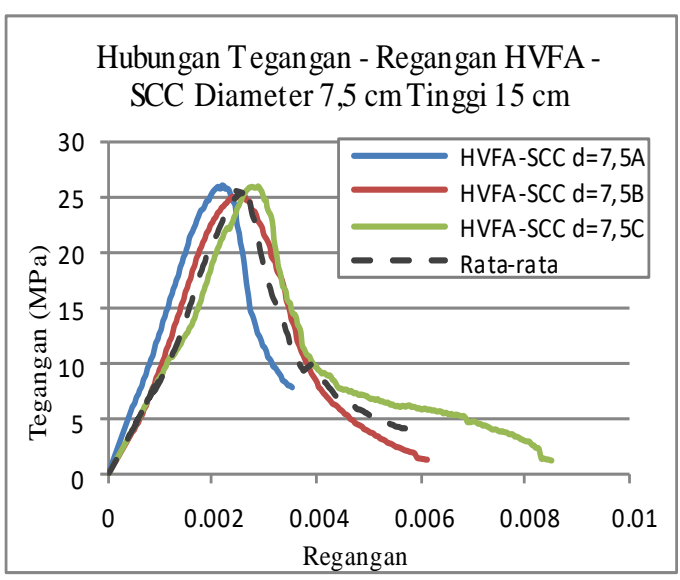

$1 \mathrm{c}$

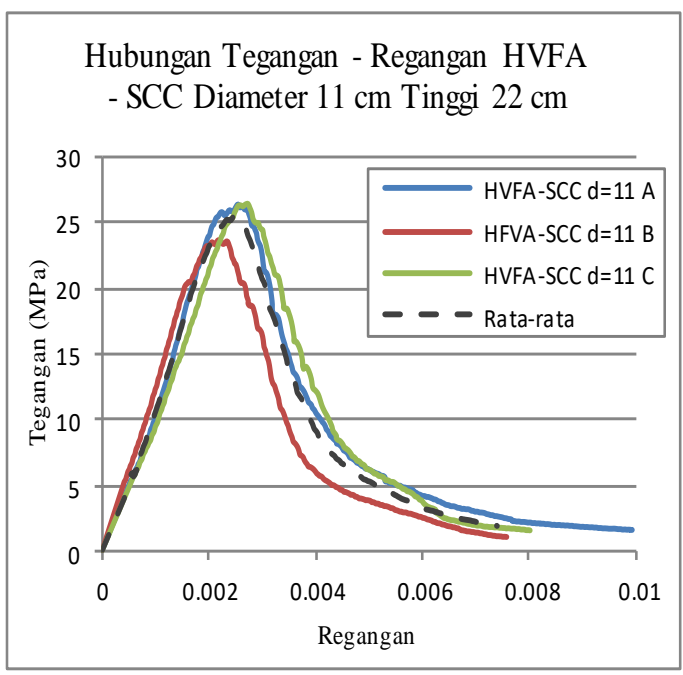

$1 \mathrm{e}$

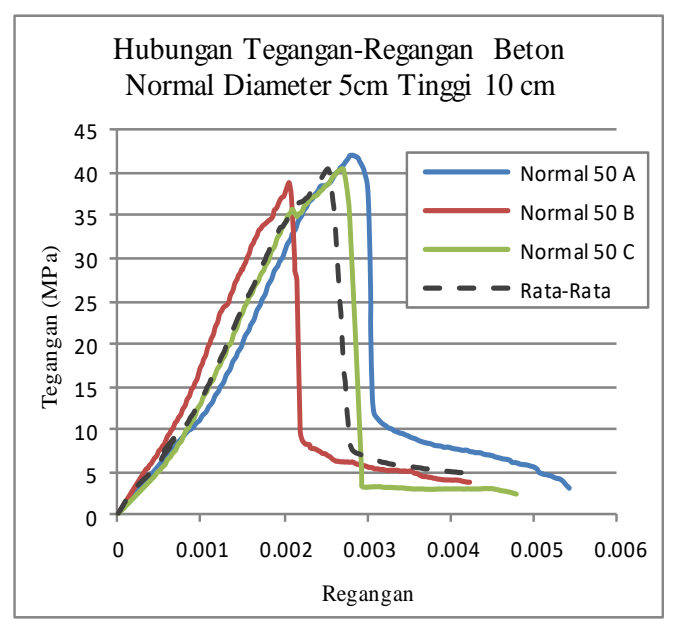

$1 \mathrm{~b}$

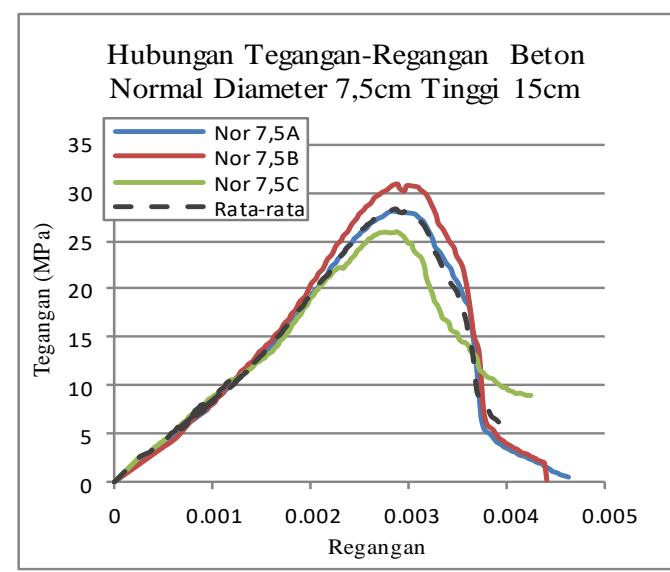

$1 \mathrm{~d}$

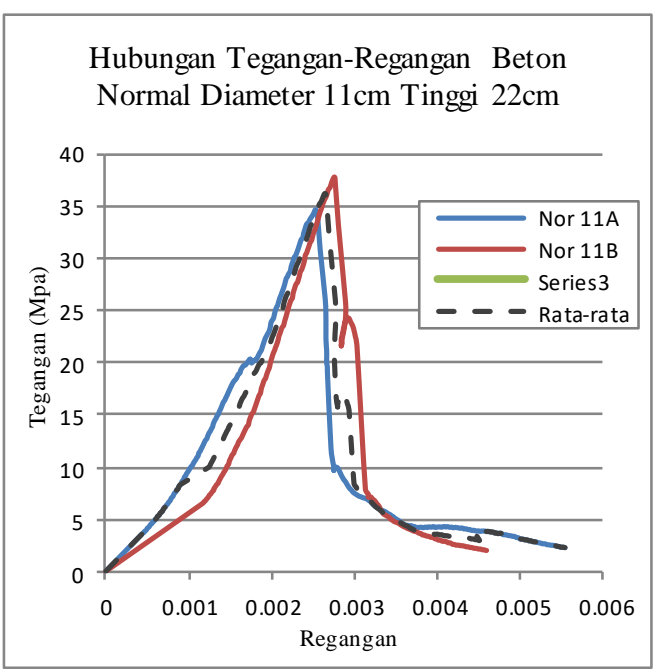

$1 \mathrm{f}$

Gambar 1. Grafik Kurva Tegangan-Regangan HFVA-SCC dan Beton Normal 
Berdasarkan Gambar 1a - 1f mengenai grafik hubungan tegangan-regangan yang ditampilkan diatas untuk masing-masing tinggi spesimen kemudian dirata-rata perkenaikan beban (P) dengan menentukan batas regangan yang akan disajikan dalam Gambar 2. sebagai berikut :
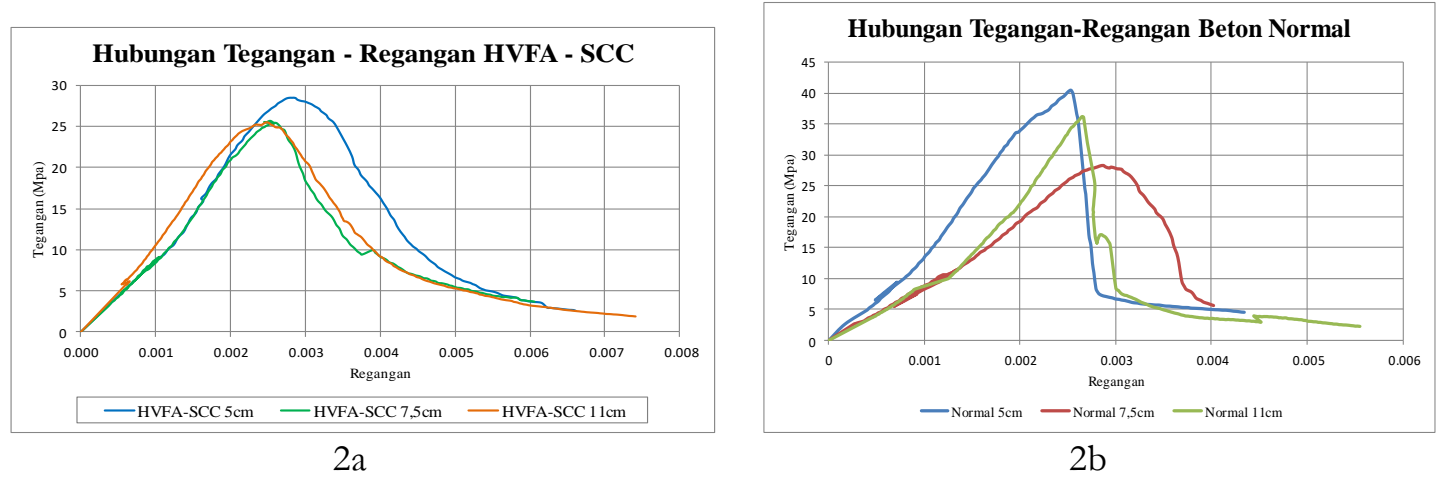

Gambar 2. Grafik Perbandingan Kurva Tegangan-Regangan

Berdasarkan gambar 2a. dan $2 \mathrm{~b}$ di atas, dapat dihitung nilai thoughness. Toughness merupakan energi yang diserap sebuah elemen pada saat pembebanan, yang menunjukan seberapa besar kemampuan sebuah elemen untuk menyebarkan secara merata energi yang diterimanya akibat pembebanan. Nilai thoughness didapatkan dari luas area yang berada di bawah grafik

Tabel 4. Nilai Toughness HVFA-SCC dan Beton Normal

\begin{tabular}{cccc}
\hline \multirow{2}{*}{ Nama Sampel } & \multicolumn{3}{c}{ Luasan di bawah Grafik } \\
\cline { 2 - 4 } & Pre Pick & Post Pick & Toughness \\
\hline HVFA-SCC 5 cm & 0,039964 & 0,046291 & 0,08625 \\
\hline Normal $5 \mathrm{~cm}$ & 0,050294 & 0,017044 & 0,06734 \\
\hline HVFA-SCC 7,5 cm & 0,031261 & 0,035059 & 0,06632 \\
\hline Normal 7,5 cm & 0,039373 & 0,046397 & 0,08577 \\
\hline HVFA-SCC $11 \mathrm{~cm}$ & 0,033948 & 0,041336 & 0,07528 \\
\hline Normal $11 \mathrm{~cm}$ & 0,03787 & 0,017496 & 0,05537 \\
\hline
\end{tabular}

Penambahan fly ash dengan kadar 50\% dari berat binder menandakan bahwa HVFA dapat menyerap dan menyebarkan energi yang lebih banyak saat pembebanan dibandingkan dengan beton normal. Penambahan fly ash ini juga mempengaruhi daerah softening pada grafik dimana luasan post-peak pada HVFA lebih besar dibanding dengan luasan post-peak pada beton normal.

Tabel 5. Nilai Daktilitas HVFA-SCC dan Beton Normal

\begin{tabular}{cccc}
\hline Nama Sampel & Regangan Maks & Regangan 0,4 f'c & Daktilitas \\
\hline HVFA-SCC $5 \mathrm{~cm}$ & $7,03 \times 10^{-3}$ & $1,29 \times 10^{-3}$ & 5,43 \\
\hline Normal $5 \mathrm{~cm}$ & $4,68 \times 10^{-3}$ & $1,15 \times 10^{-3}$ & 4,07 \\
\hline HVFA-SCC $7,5 \mathrm{~cm}$ & $6,06 \times 10^{-3}$ & $1,18 \times 10^{-3}$ & 5,13 \\
\hline Normal 7,5 cm & $6,80 \times 10^{-3}$ & $1,33 \times 10^{-3}$ & 5,12 \\
\hline HVFA-SCC $11 \mathrm{~cm}$ & $7,40 \times 10^{-3}$ & $0,97 \times 10^{-3}$ & 7,64 \\
\hline Normal $11 \mathrm{~cm}$ & $5,55 \times 10^{-3}$ & $1,54 \times 10^{-3}$ & 3,61 \\
\hline
\end{tabular}


Besarnya nilai daktilitas HVFA-SCC dibanding beton normal menunjukkan bahwa beton HVFASCC mampu bertahan hingga keruntuhan lebih lama dibandingkan beton normal yang cenderung lebih getas.

Dalam penelitian ini juga menguji data kenaikan deformasi secara lateral, yang kemudian didapatkan hasil grafik tegangan-regangan lateral yang disajikan dalam Gambar 3.

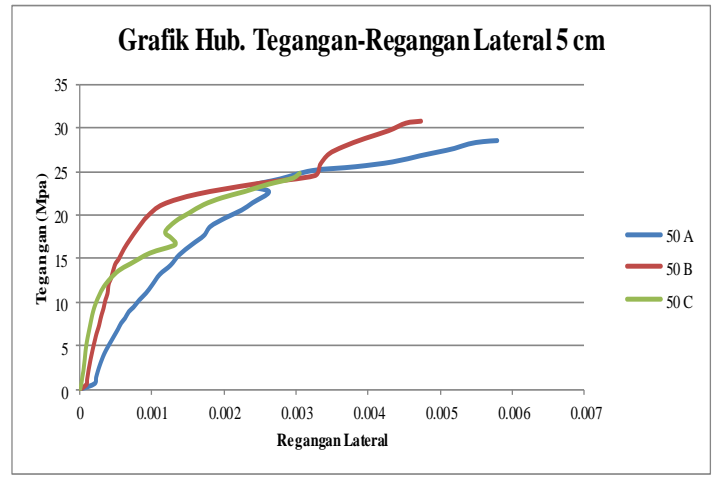

$3 \mathrm{a}$

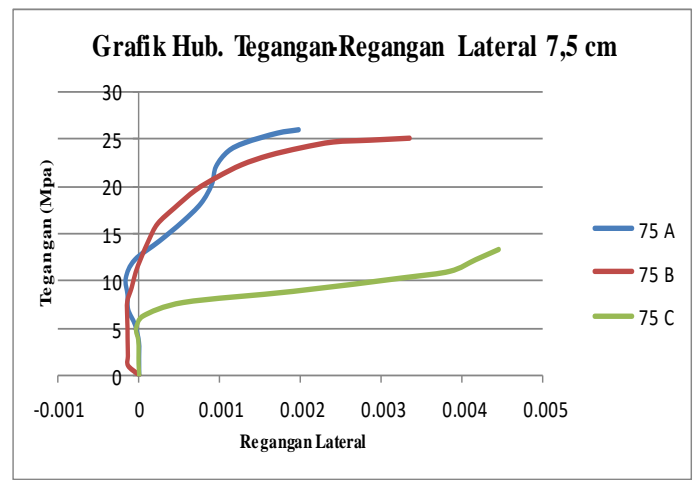

$3 \mathrm{~b}$

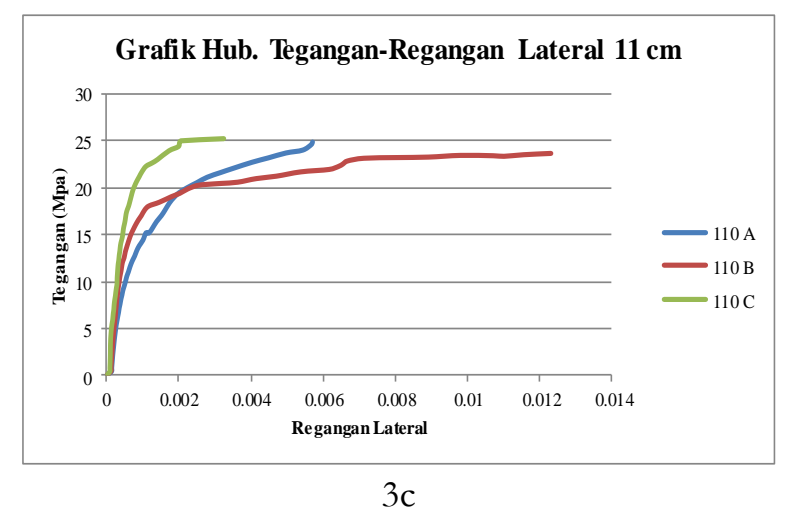

Gambar 3. Grafik Hubungan Tegangan-Regangan Lateral pada HVFA-SCC

Berdasarkan Gambar 3a, 3b, dan 3c diambil perbandingan besarnya regangan lateral pada tegangan yang sama sebesar $5 \mathrm{MPa}$ yang dianggap mampu mewakili semua sampel benda uji.

Tabel 6. Perbandingan Besar Regangan Lateral pada Tegangan yang Sama

\begin{tabular}{ccccc}
\hline No & Nama Sampel & $\begin{array}{c}\text { Tegangan } \\
(\mathbf{M P a})\end{array}$ & Regangan Lateral & \multirow{2}{*}{ Rata-rata } \\
\cline { 1 - 4 } 1 & HVFA 50 A & 5 & $3,94 \times 10^{-4}$ & \multirow{2}{*}{$2,23 \times 10^{-4}$} \\
\cline { 1 - 4 } 2 & HVFA 50 A & 5 & $1,88 \times 10^{-4}$ & \\
\hline 3 & HVFA 50 A & 5 & $0,87 \times 10^{-4}$ & \multirow{2}{*}{$-0,74 \times 10^{-4}$} \\
\hline 4 & HVFA 75 A & 5 & $-0,42 \times 10^{-4}$ & \\
\hline 5 & HVFA 75 A & 5 & $-1,45 \times 10^{-4}$ & \\
\hline 6 & HVFA 75 A & 5 & $-0,36 \times 10^{-4}$ & \\
\hline 7 & HVFA 110 A & 5 & $2,00 \times 10^{-4}$ & \\
\hline 8 & HVFA 110 A & 5 & $2,12 \times 10^{-4}$ & \\
\hline 9 & HVFA 110 A & 5 & $1,40 \times 10^{-4}$ & \\
\hline
\end{tabular}


Dari table di atas dapat disimpulkan bahwa pada tegangan yang sama yaitu 5 MPa pada benda uji diameter $5 \mathrm{~cm}$ dan $11 \mathrm{~cm}$ memiliki rata-rata tegangan lateral yang hampir sama berkisar pada nilai 0.0002. sedangkan untuk benda uji diameter $7,5 \mathrm{~cm}$ memiliki perbedaan nilai yang cukup jauh. Hal ini dapat terjadi dikarenakan beberapa faktor kemungkinan, salah satunya pemasangan strain gange pada permukaan beton maupun saat setting alat pembaca strain gange.

\section{Kesimpulan}

Berdasarkan hasil analisa dan pembahasan di atas dapat disimpulkan bahwa pada perbedaan ukuran spesimen dengan rasio perbandingan diameter dan tinggi tetap memiliki karakteristik yang hampir sama. Jika dibandingkan antara HVFA-SCC dengan beton normal, maka terlihat beberapa perbedaan:

a. Kuat desak beton normal lebih tinggi dibanding HVFA-SCC karena reaksi antara fly ash dengan hasil sekunder semen dan air yaitu $\mathrm{Ca}(\mathrm{OH})_{2}$ untuk pembentukan C-S-H gel masih kurang optimal pada umur 28 hari.

b. Hal ini berarti adanya penambahan fly ash dengan kadar 50\% dari berat binder menandakan bahwa HVFA dapat menyerap dan menyebarkan energi yang lebih banyak saat pembebanan dibandingkan dengan beton normal.

c. HVFA-SCC memiliki nilai daktilitas lebih besar dibanding beton normal. Hal ini menunjukkan bahwa beton HVFA-SCC mampu bertahan hingga keruntuhan lebih lama dibandingkan beton normal yang cenderung lebih getas.

\section{Daftar Pustaka}

Anonim. "ASTM C 469 Standart Test Method for Static Modulus of Elasticity and Poisson's Ratio of Concrete in Compression"

ASTM C39/C39M "Standard Test Method for Compressive Strength of Concrete"

EFNARC “Specification and Guidelines for Self-Compacting Concrete”, 2002

H. Ladwig et al. "Self Compacting Concrete - Principles and Practice," Concrete Plant + Precast Technology, pp. 58-67, June 2001

J.R. del Viso et al. 2008. "Shape and Size Effects on the Compressive Strength of High - Strength Concrete". Article in Concrete and Research.

Ladwing H, II - M., Woise, F., Hemrich, W. and Ehrlich,N

N. Paul and Antoni, Edisi 1 : Teknologi Beton dan Material, Pembuatan, ke Beton Kinerja Tinggi ; 2001, pp. 47

V. M. Malhotra and P. K. Mehta, High Performance, High-Volume Fly Ash Concrete: materials, mixture proportioning, properties, construction practice, and case histories. $2^{\text {nd }}$ ed. Supplementary Cementing Materials for Sustianable Development Inc., Ottawa, Canada; 2005 